\title{
Explaining the Concept and Operations of Integer in Primary School Mathematics Teaching: Opposite Model Sample
}

\author{
Hatice Cetin \\ Faculty of Education, Karamanoglu Mehmetbey University, Turkey
}

Copyright $\mathrm{O} 2019$ by authors, all rights reserved. Authors agree that this article remains permanently open access under the terms of the Creative Commons Attribution License 4.0 International License

\begin{abstract}
Many related studies have studied many different models in the teaching of the concept of integer, which have reported that counters failed to completely help with the understanding of the concept of and operation modeling in integers. The purpose of the present research is presenting the "opposite model", which is a quantitative model, unlike thermometer, elevator, sea level, or number line, which are directional models. Additionally, it presents solutions to the problem of learning the concept of and operations in integers through models used in teaching integers for primary school $6^{\text {th }}$ grade students. Opposite model is an integer model, which is based on theory and enables the easy learning of the concept of integers and addition and subtraction operations tested with experimental study by [9]. The present research is believed to contribute students' meaningful learning of the concept and operations of integers and alternative thinking through opposite model. The present research discusses the necessity of opposite model, which is to be offered as an alternative mathematical model for teaching the concept of integers and addition-subtraction operations, in light of the findings obtained through literature review.
\end{abstract}

Keywords Concept of Quantity, Integer Teaching, Opposite Model, Meaningful Learning, $6{ }^{\text {th }}$ Grade

\section{Introduction}

The concept of integer is the basis of algebra learning domain in primary school mathematics teaching and it is considered as an important pre-condition for mathematics course. Additionally, this concept symbolizes the transition from concrete thinking to abstract thinking [1]. Although first standards suggest that integers should be learnt at $3^{\text {rd }}$ grade [2]; latest standards disapprove of the teaching of the concept of integer before $6^{\text {th }}$ grade, and integer operation before $7^{\text {th }}$ grade [3]. The role of the methods and models is important since $6^{\text {th }}$ grade students, who are in the period of transition from concrete operations to abstract operations, encounter the concept of integer for the first time. In the past, the concept and operations of integers were taught through algebraic rules, instead of explaining with models. Innovative strategies include various methods and models to help students learn and understand the abstract ideas including integer calculations. The importance of modeling studies is no longer a matter of debate in mathematics teaching. Groups studying with mathematical modeling activities have been reported to be more successful in associating mathematics with daily life than those who don't study with these activities [4]. However, modeling should have a purpose of explaining concepts and operations. They can't serve their purpose otherwise. Additionally, it is important that models are based on theoretic foundations.

Mathematicians and mathematic teachers have suggested and used many models in integer teaching. [5-8]. So far, many different models such as counters, elevation, thermometer, hot air balloon, sea level model, directional objects and debit-credit models. These models were defined as quantity models and directional models in the related literature. Quantity models include models, such as red-black counters and debit-credit, while directional models include number line, elevation, thermometer, and sea level. Accordingly, we can claim that integer models are covered in two categories (quantity and directional models) in the related literature. Golf scores, money (asset-dept), football (average), etc. [8], magic peanut [26] are some examples of quantity concepts formed in this scope. Some examples of linear (directional) concepts are temperature, sea level, time line, etc. [8]. The teaching material developed by [9] supported experimental study for integer teaching in accordance with multiple representation approach, used opposite model and counters model in the framework of quantitative concepts, and thermometer 
model, elevation model, number line model and sea level model in the framework of directional concepts.

Number line model (directional model) is very important in learners' forming a conceptual structure while learning mathematics [10]. Number line is defined as the basic metaphor in understanding mathematics [11]. It was claimed that using number line was inevitable in developing the sense of number and understanding arithmetic [11]. However, mathematics educators questioned the appropriateness of this model in modeling integer operations (Battista, 1983; Liebeck, 1990; as cited in:[14],[12]. While the importance of number line model in integer teaching is known, the strongest criticism against this model is that model fails to explain the subtraction operation. In relation to that, Liebeck (1990), considers number line model enough in explaining operations producing only negative results, in other words, subtracting a positive number from a negative number or subtracting a positive number from a greater positive number. For instance explaining operations $-3-(+5)$ or $3-(+5)$ is reasonable. However, it is understood that it inadequate in explaining operations, such as 3-(-5) or $-3-(-5)$. The best models to apply in such cases are quantity models.

"Equality or quantity model" in integer teaching is based in the marked quantity idea, and is a model showing $-\mathrm{n}$ is less than 0 -zero [13]. In this model, integers are explained through opposite concepts (positive-negative, proton-electron or asset-dept). In this model, addition operation is defined as adding quantities together (two opposite quantities that equal to zero); and subtraction operation as subtracting quantities or adding their opposites. In quantity and opposite models, quantity is explained with the quantity of counters and the concept of opposite is explained with the colors of counters [8].

Sherzer (1973) compared the differences between number line and quantity models in integer teaching. They conducted an experimental study on two $6^{\text {th }}$ grade classes of 30 students, and reported that opposite-quantity models were more effective in developing the concept and related skills cited in: [14]. Liebeck (1990) reported similar results in the study comparing number line and quantity model cited in: [14]. Opposite magnitudes contribute to learners' reasoning in association with integer understanding [15]. In fact, integer reasoning results from the early developed senses on the opposite magnitude among learners [15].

Negative numbers are difficult to understand and conceptualize. Although students don't have any difficulty in placing negative numbers on number line, they have problems in comparing the value of them. The greatest problem encountered with operations in negative numbers is the use of "+" and "-" symbols, which also represent addition and subtraction operations $[8,16]$. Similarly, [17] suggested that making operations with two positive numbers weren't difficult for learners, while defining negative numbers and operations with two negative numbers or one positive ne negative number were hard to understand for them. Formulating negative numbers came along with some difficulties. The most common problem is related with the double use of negative symbol. In the early $18^{\text {th }}$ century, some mathematicians stated that using double negative symbol was problematic and difficult to learn [18]. This difficulty encountered by learners has three main reasons; 1) the symbol - is used both for the operation and the direction, 2) conceptual contradiction between the quantitative arithmetic meaning of number and both senses of "quantity" and "direction", 3) the lack of a practical model explaining the features of negative number system [19].

For instance, learners can easily make the operation $(-2)+(-4)=-6$ reasoning through $2+4=6$ equality. However, they consider 2-(-4) addition operation as 2-4. Similarly, $5^{\text {th }}$ grade students, who didn't have negative number concept, tried to make operation $5-7$ as $7-5$ and $-5+8$ as $5+8$ [19]. Mindscapes of learners related to numbers are limited to cardinal numbers. When they learn something new, they try to understand in relation with their previous mindscapes [20]. However, when learners encounter negative numbers, they cannot relate to their previous learning of cardinal numbers [16].

Undoubtedly, one of the most important factors in correction misconceptions among learners is the pedagogical content knowledge of in-service and pre-service teachers. Yet, learners' understanding the concepts is not only possible with teachers' providing related rules and information. Teachers with strong content knowledge use details instead of superficial knowledge and rules, relate the subject with other subjects and they don't just follow the course book. On the other hand, teachers with weak content knowledge were reported to prefer presenting mathematical facts as rules without providing rational explanations and sticking to their lesson plans [2]. At this point, operations in integers should be presented through models instead of presenting the rules directly, and learners should be enabled to form their own schemas on their minds and create their own rules accordingly. The related literature includes many alternatives for directional models, while quantity models are limited to counters. For instance, there are studies that report that teachers have negative opinions about the learning difficulties in learning through modeling with counters, which were coined in 1970s. On this issue, teachers suggested that learners had difficulty in understanding why they should use the plus symbol while subtracting a negative integer from a positive integer [32]. Additionally, teachers reported that counters made the learning process difficult, but they had to prefer modeling with counters since they didn't have enough content knowledge on the different modeling methods [32]. Besides, studies on how pre-service teachers present the subject of integers to their students [16,32] showed that pre-service teachers' instructional explanations were generally at operational level. Teachers require meaning models that help students form schemas on their minds so 
that they can present the subject, which forms the basis of algebra, at a conceptual levels, because learners cannot realize a deep meaningful learning as long as they are just provided with rules [16]. On this issue, a study includes suggestions for enriching alternative models and activities that teachers can use in their classes [32].

Course books and curricula have been observed to model addition and subtraction operations yet these lacked in number in terms of quantity modeling. On this issue, is reported that $6^{\text {th }}$ grade curriculum included limited concepts and examples on the concept of integer and operations [27]. For example, number -3 is modeled as (---). This model would make subtraction operations $-3-5$ or $-3-(-5)$ meaningless later. This creates a loophole in integer teaching. Taken the difficulties learners experience in subtraction, conceptual learning is required for the learners learn operations meaningfully, which requires the modeling of integers. If the integer can be modeled first, then operations of adding another integer to this or subtracting another integer from this can be modeled easily.

The present research offers solutions to the problems primary school second level students experience in explaining the concept of and operations in integers. It discusses the necessity of opposite model, which is to be offered as an alternative mathematical model for teaching the concept of integers and addition-subtraction operations, in light of the findings obtained through literature review.

\section{Framework}

\subsection{The Concept of Integer}

The set defined as $\{(\overline{a, b}):(a, b) \in \mathbb{N} x \mathbb{N}\}$ equilibrium being $(\overline{a, b})$ according to $\sim$ relation defined as "for $(a, b) \sim(c, d)$ on $\mathbb{N} x \mathbb{N}$ set, if and only if $a+d=b+c$ " is called as set of integers and $(\overline{a, b})$ is an integer $[21,28]$. The set of integers is traditionally represented with $\mathbb{Z}$.

Addition in $\mathbb{Z}$ set of integers is defined as follows, and each of these is an operation:

If $(a, b),(c, d) \in \mathbb{N} x \mathbb{N}$, then $(\overline{a, b})+(\overline{c, d})=$ $(\overline{a+c, b+d})$.

Additionally, if $(\overline{a, b}) \in \mathbb{Z}$, then opposite of $(\overline{a, b})$ under addition is $(\overline{b, a})$ and so $-(\overline{a, b})=(\overline{b, a})$ [21].

According to the definition above, for any integer to be defined as an $(\overline{a, b})$ ordered pair, a refers to positive and $b$ refers to negative. In this case opposite model is explained through relating with quantity concepts.

This new set of elements according to the above definition can be schematically shown as follows [29].

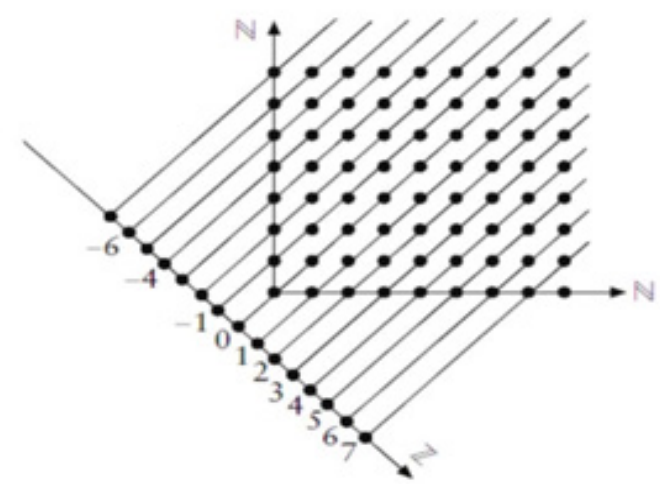

Figure 1. A model by [29]

The opposite model, which was developed in regard to the learning difficulties resulting from modeling with counters, and the mathematical philosophy it is based on, is presented below.

\subsection{Opposite Model-Equilibrium}

An integer is defined as an ordered pair in a model set in accordance with the definition above. For instance, the integer 3 can be presented in ordered pairs as $(3,0),(4,1)$, $(5,2)$. The first component of these ordered pairs represents the positive, while the seconder presents the negative. Since $-(\overline{a, b})=(\bar{b}, a)$ in accordance with the mathematical definition above, -3 as the opposite of 3 under addition is verified as $-(\overline{0,3})=(\overline{3,0})$. Similarly, modeling the integer -4 as $(0,4),(1,5),(2,6),(3,7)$ ordered pairs will help in understanding the operation models presented below. The interface of the manipulative developed supported experimental study [10] to better explain the opposite model suggested in the study by [10] is as presented in Figure 2:
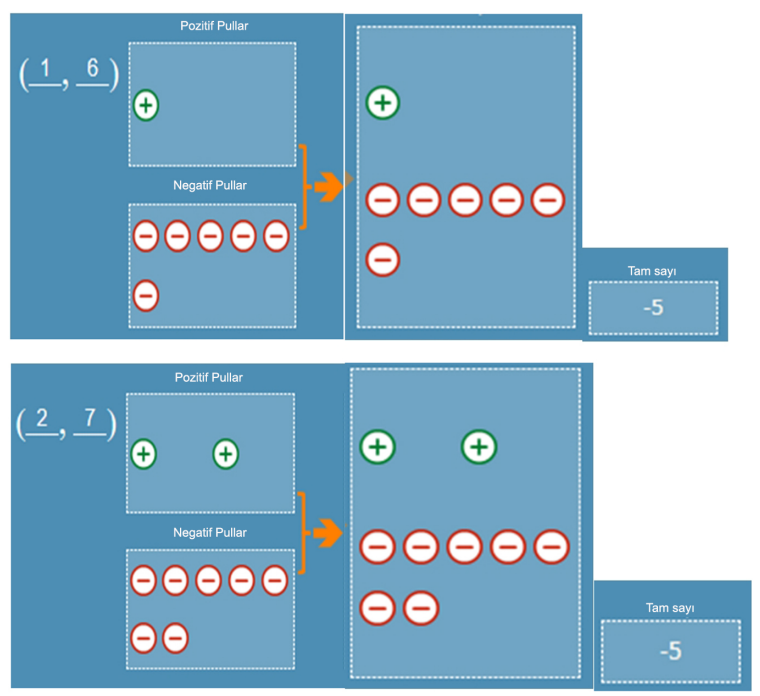

Figure 2. A model developed by [10] used for the concept of integer in virtual manipulative: opposite model 
This manipulative includes counters for ordered pairs and their integer equivalents. Presenting an integer's potential positive and negative cases is possible. Additionally, infinite number of ordered pairs can be represented in accordance with an integer's equivalent relation strategy. Moreover, $(1,6)=-5$ integer model is and explanatory model for the addition operation, $+1+(-6)=-5$. Similarly, $(2,7)=-5$ integer model explains the addition operation $+2+(-7)=-5[28]$.

Integers explained with ordered pairs [22]. The presentation of ordered pairs explaining integers according [22] is shown in Figure 3.

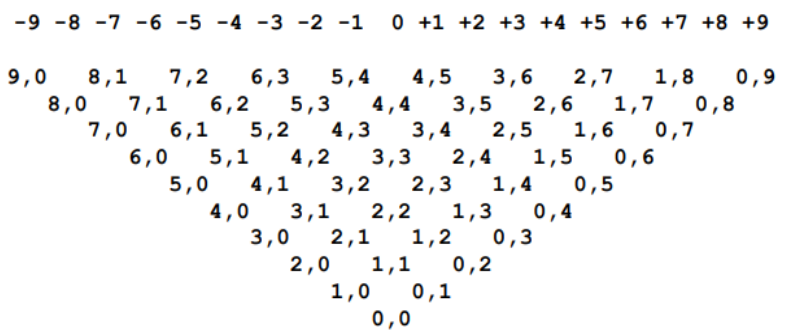

Figure 3. The integer model according to [22]

Integer representations in the above number line; for instance ordered pair $(3,4)$, explains that the second component is 1 greater than the first component. In this model, positive and negative meanings explained by the first and second components of the ordered pairs defined in the opposite model are defined differently. In other words, first component explains the negative case, while second explains the positive. In the opposite model definition of the researcher, this case is the opposite; as the first component explains the positive and the second explains the negative case, and the integers are explained through the addition of these ordered pairs. However, it is similar to the opposite model as number pairs with no difference represent zero $((0,0)=(1,1)=(2,2)=$ $(3,3)=\cdots)$.

In another similar study analyzing the integer reasoning ways of $1^{\text {st }}, 3^{\text {rd }}$ and $5^{\text {th }}$ grade students [15], models formed by learners in accordance with their reasoning models were explained with $(a, b)$. Learners, who had never received any education on integers, could easily express that $(1,6)$ and $(2,7)$ models were equal.

Above mentioned modeling is as in Figure 4:

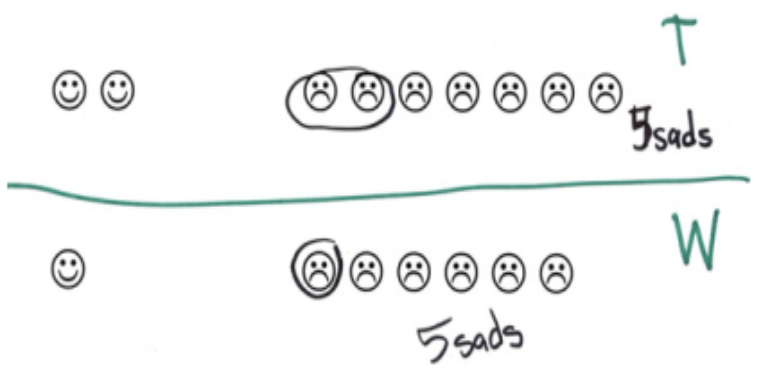

Figure 4. A visual about comparing $(2,7)$ with $(1,6)$ in the study by [15]
In the study, happy and sad thought opposite concepts were used and $1^{\text {st }}$ and $3^{\text {rd }}$ grade students' tried to explain the integer comparisons $(a, b)$ through equilibrium. About the quantity and opposite concepts, learners compared happy and sad events experienced on Tuesday and Wednesday as happy day-sad day (opposite magnitudes) in terms of the numbers of happy and sad events.

It was claimed that every integer could be explained with two cardinal numbers [21]. For instance: +3 , $4-1=10-7=12-9$ or $-2,1-3=5-7=18-20$. On marked cardinal numbers, $(m, n) \sim(p, q)$ if and only if $m+q=p+$ $n$ [21]. In this context, this case is provided in the structure defined as opposite model. In other words, $(1,3) \sim(2,4)$ if and only if $(1+4=2+3)$. Additionally, according to the definition, an integer has infinite number of explanatory representations; as -2 can be represented as $(1,3),(2,4),(3,5),(4,6),(5,7),(6,8)$, $(7,9)$, etc.

Similar to the idea of an integers' modeling infinitely, ratio pairs being modeled infinitely can be observed in equilibrium strategy defined by [30] Accordingly, for the ratio $1 / 5,(2$ laps $/ 10$ minutes $=4$ laps $/ 20$ minutes $=8$ laps / 40 minutes) ratio pairs can be provided. Thus, forming infinite equilibrium models representing an integer as in forming equilibrium representing a ratio or a rational number enables alternative modeling. On the other hand, [23] defines the one of the 30 components of sense of number as "using and understanding equivalent forms and representations of numbers". For instance, expressing the integer 3 in equivalent forms as $(3,0),(4,1),(5,2),(6,3)$, etc. Or the integer -4 as $(0,4),(1,5),(2,6),(3,7)$ equivalent forms constitutes the basis of operation modeling. Being able to modeling integers will ease the process of operation, which is the next step. Modeling numbers means the understanding the mentality of addition operation, and also eases the understanding of subtracting operation, which can be difficult through counters. For example, instead of adding or subtracting number pairs while modeling subtraction -3-5 with counters, it can presented through opposite model- equilibrium strategy as follows: Modeling for subtraction -3-5 is presented in Figure 5.

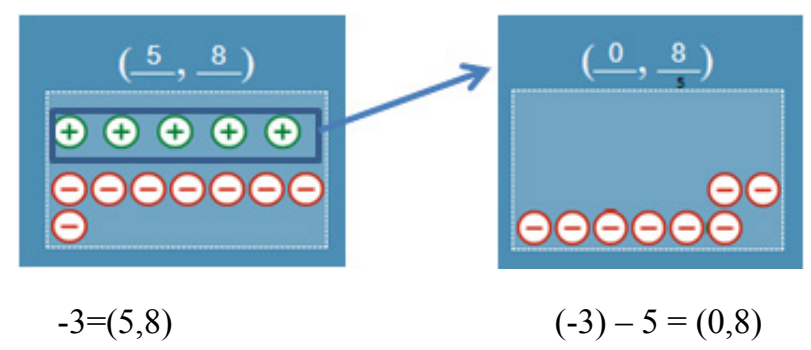

Figure 5. Opposite model for subtraction $-3-5$

A reasonable ordered pair is written for integer -3 . While ordered pairs $(0,3),(1,4)$, etc. can be written for integer -3 , choosing $(5,8)$ model is the actual indicator of reasoning skill, and can explain the result easily and clearly. 
Subtracting an integer from another integer (positive from positive, negative from positive, positive from negative, negative from negative) is not a problem, because 5 (positive) in -3 potential is modeled and explained in the first place. When 5 is subtracted from $(5,8)$, the result is $(0,8)$, which is the model explaining integer -8 which is the equivalent of 8 negative.

The operation of subtracting a positive integer from any other integer is made meaningful in a directional model by modeling as counting directly backward. Indeed, since the operation of subtracting a negative integer from any integer cannot be explained meaningfully on a directional model, this operation is modeled through opposite model. As an example, modeling for subtraction $-3-(-5)$ is as presented in Figure 6.

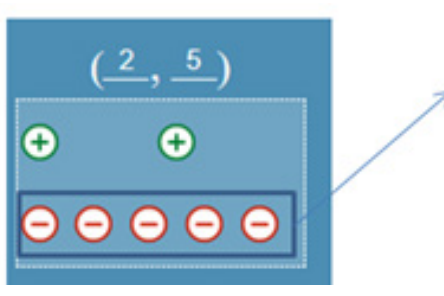

$-3=(2,5)$

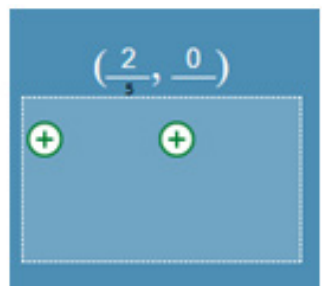

$-3-(-5)=(2,0)$
Figure 6. Opposite model for subtraction $-3-(-5)$

A reasonable ordered pair is written for integer -3 . Modeling integer -3 as $(2,5)$ is to show the 5 negative $(-5)$ in its potential. When negative 5 is subtracted from $(2,5)$ the result is $(2,0)$, which is integer 2 corresponding 2 positive.

\section{Conclusions and Discussion}

Developed opposite model is presented an alternative model for basic integer teaching. The present research is important as it meets the need for developing meaningful alternative model for the concept and operations of integers $[24,32]$. It is also important as it provides solutions to the encountered problems reported in some previous studies $[8,12,16,17,18,19]$.

Opposite model contributes to the modeling process by making all addition and subtraction operations meaningful. Additionally, opposite magnitudes have been reported to contribute to learners' reasoning in relation with their understanding integers [15], and to have a positive effect in concept development and acquiring skills (Sherzer, 1973; cited in: [14]; [10]. Using only directional models in integer teaching was considered inadequate (Battista, 1983; Liebeck, 1990; as cited in: [14]; [25]. Accordingly, the opposite model developed as a different quantity model within the scope of the present research is consistent theoretically as it contributes to the development of the concept of integer and integer reasoning.

The opposite model has been developed in accordance with the mathematical definition the concept of integer $[21,28,29]$ and it enables the modeling of an integer as an ordered pair. After the modeling the integers, it provides meaningful learning for addition and subtraction operations. The use of opposite model as one of the integer representations can also be seen in the study conducted by [22]. The place of the components of the ordered pairs defined by the researchers is different from his representation. It is similar to the opposite as ordered number pairs with no difference, such as $(1,1),(2,2)$, $(3,3), \ldots$ (n, n), etc. represent 0-zero. Additionally, integer representations are defined as ordered pairs in the study conducted by [31]. Moreover, it is interesting that $1^{\text {st }}$ level students, who had never received any instruction on the integers, tried to explain integer comparisons this way. Equivalence strategy in ratio teaching developed by [30] is also another strategy used by forming infinite ratio pairs. As a matter of fact, [23] defines one of the components of the sense of number as "using and understanding the equivalent forms and representations of numbers". In this context, the use of infinite equivalent forms of numbers is important for the development of the sense of number.

In teaching the concept and operations of integers, doing integer modeling exercises with the help of opposite model also providing meaningful learning by using the contrast model for addition and subtraction operations is recommended.

\section{REFERENCES}

[1] Lamb, L.C. and E. Thanheiser, Understanding integers: Using balloons and weights software. Algebraic Thinking, 2006. 2: p. 163-164.

[2] NCTM, Principles and standards for school mathematics. Vol. 1. 2000.

[3] NGA, Common core state standards. Light, J, 2010. 19: p. 19.

[4] Doruk, B.K. and A. Umay, Matematiği günlük yaşama transfer etmede matematiksel modellemenin etkisi. Hacettepe Üniversitesi Eğitim Fakültesi Dergisi, 2011. 41(41).

[5] Badarudin, B.R.H. and M. Khalid, Using the Jar Model to Improve Students' Understanding of Operations on Integers. Proceedings Of Icme-11-Topic Study Group 10 Research And Development In The Teaching And Learning Of Number Systems And Arithmetic, 2008: p. 85.

[6] Lestari, U.P., R.I.I. Putri, and Y. Hartono, Using Set Model for Learning Addition of Integers. Journal on Mathematics Education, 2015. 6(2): p. 93-106.

[7] Steiner, C.J., A study of pre-service elementary teachers' conceptual understanding of integers. 2009, Kent State University.

[8] Van de Walle, J.A., et al., Elementary and middle school 
mathematics: Teaching developmentally. 2007.

[9] Çetin, H., Sorgulayıcı öğrenme yaklaşımıla çoklu temsil destekli tam sayı öğretiminin 6. sinif öğrencilerinin başarılarına, model tercihlerine ve temsiller arası geçiş becerilerine etkisi. Necmettin Erbakan Üniversitesi, Eğitim Bilimleri Enstitüsü, Yayınlanmamış Doktora Tezi, 2016.

[10] Moreno, R. and R.E. Mayer, Multimedia-supported metaphors for meaning making in mathematics. Cognition and instruction, 1999. 17(3): p. 215-248.

[11] Nunez, R.E. and G. Lakoff, The metaphorical structure of mathematics: Sketching out cognitive foundations for a mind-based mathematics, in Mathematical reasoning. 2013, Routledge. p. 29-98.

[12] Bofferding, L. Addition and subtraction with negatives: Acknowledging the multiple meanings of the minus sign. in Proceedings of the 32nd annual meeting of the North American Chapter of the International Group for the Psychology of Mathematics Education. 2010.

[13] Goldin, G. and N. Shteingold, Systems of representations and the development of mathematical concepts. The roles of representation in school mathematics, 2001. 2001: p. 1-23.

[14] Bolyard, J.J., A comparison of the impact of two virtual manipulatives on student achievement and conceptual understanding of integer addition and subtraction. 2006: George Mason University.

[15] Whitacre, I., et al., Happy and sad thoughts: An exploration of children's integer reasoning. The Journal of Mathematical Behavior, 2012. 31(3): p. 356-365.

[16] Reeder, S. and S. Bateiha, Prospective Elementary Teachers' Conceptual Understanding of Integers. Investigations in Mathematics Learning, 2016. 8(3): p. 16-29.

[17] Altun, M., Matematik öğretimi. Erkan Matbaacılık, Bursa, 2005.

[18] Carson, C.L. and J. Day, Annual Report on Promising Practices: How the Algebra Project Eliminates the. 1995.

[19] Hativa, N. and D. Cohen, Self learning of negative number concepts by lower division elementary students through solving computer-provided numerical problems. Educational Studies in Mathematics, 1995. 28(4): p. 401-431.

[20] Vosniadou, S., The Framework Theory Approach to the Problem of Conceptual Change, in International Handbook of Research on Conceptual Change. 2009, Routledge. p. 31-62.

[21] Argün, Z., et al., Temel matematik kavramların künyesi. Ankara: Gazi Kitabevi, 2014.

[22] Dienes, Z.P., The theory of the six stages of learning with integers. Mathematics in School, 2000. 29(2): p. 27-32.

[23] Berch, D.B., Making sense of number sense: Implications for children with mathematical disabilities. Journal of learning disabilities, 2005. 38(4): p. 333-339.

[24] Kumar, R.S. and K. Subramaniam, From'Following'to Going Beyond the Textbook: Inservice Indian Mathematics Teachers' Professional Development for Teaching Integers. Australian Journal of Teacher Education, 2015. 40(12): p. 7.
[25] Bossé, M.J., et al., Using integer manipulatives: Representational determinism. International Journal for Mathematics Teaching and Learning, 2016. 17(3): p. n3.

[26] Ball, D.L., With an eye on the mathematical horizon: Dilemmas of teaching elementary school mathematics. The elementary school journal, 1993. 93(4): p. 373-397.

[27] National Council of Educational Research and Training(2006). Mathematics: Textbook for classVI. Retrieved from http://www.ncert.nic.in/ncerts/textbook/text book.htm? femh1=6-14

[28] Baki, A. (2018). Matematiği öğretme bilgisi. Pegem Akademi, Ankara.

[29] Nesin, A., Sayıların İnşası. Open Course Ware Consortium Project, 2010.

[30] Bart, W.M., A Diagnostic Analysis of a Proportional Reasoning Test Item: An Introduction to the Properties of a Semi-Dense Item. Focus on learning problems in mathematics, 1994. 16(3): p. 1-11.

[31] Whitacre, I., Bishop, J. P., Lamb, L. L., Philipp, A., Schappelle, B. P., \& Lewis, M.L. (2012). Happy and sad thoughts: An exploration of children's integer reasoning. The Journal of Mathematical Behavior, 31(3), 356-365.

[32] Bozkurt, A., \& Polat, M. (2011). Sayma pullariyla modellemenin tam sayılar konusunu öğrenmeye etkisi üzerine öğretmen görüşleri. Gaziantep University Journal of Social Sciences, 10(2), 787-801.

[33] Toluk Uçar, Z. (2011). Öğretmen adaylarının pedagojik içerik bilgisi: öğretimsel açıklamalar. Türk Bilgisayar ve Matematik Eğitimi Dergisi, 2(2). 